\title{
The Influence of the Anastomosis Angle on the Hemodynamics in the Distal Anastomosis in the Infrainguinal Bypass: an In Vitro Study
}

\author{
T. GRUS ${ }^{1}$, G. GRUSOVÁ ${ }^{2}$, L. LAMBERT ${ }^{3}$, R. BANERJEE ${ }^{3}$, J. MATĚCHA ${ }^{4}$, M. MLČEK ${ }^{5}$ \\ ${ }^{1}$ Second Department of Surgery, First Faculty of Medicine, Charles University in Prague, Prague, \\ ${ }^{2}$ Fourth Department of Internal Medicine, First Faculty of Medicine, Charles University in Prague, \\ Prague, ${ }^{3}$ Department of Radiology, First Faculty of Medicine, Charles University in Prague, Prague, \\ ${ }^{4}$ Department of Fluid Dynamics and Power Engineering, Faculty of Mechanical Engineering, Czech \\ Technical University in Prague, Prague, ${ }^{5}$ Department of Physiology, First Faculty of Medicine, \\ Charles University in Prague, Prague, Czech Republic
}

Received September 3, 2015

Accepted December 11, 2015

On-line March 15, 2016

\begin{abstract}
Summary
The geometric shape of the distal anastomosis in an infrainguinal bypass has an influence on its durability. In this article, we compared three different angles of the anastomosis with regard to the hemodynamics. Three experimental models of the distal infrainguinal anastomosis with angles of $25^{\circ}, 45^{\circ}$, and $60^{\circ}$ respectively were constructed according to the similarity theory to assess flow in the anastomoses using particle image velocimetry and computational fluid dynamics. In the toe, heel, and floor of the anastomosis that correspond to the locations worst affected by intimal hyperplasia, adverse blood flow and wall shear stress were observed in the $45^{\circ}$ and $60^{\circ}$ models. In the $25^{\circ}$ model, laminar blood flow was apparent more peripherally from the anastomosis. In conclusions, decreasing the distal anastomosis angle in a femoropopliteal bypass results in more favorable hemodynamics including the flow pattern and wall shear stress in locations susceptible to intimal hyperplasia.
\end{abstract}

\section{Key words}

Anastomosis • Intimal hyperplasia • Hemodynamics • Angle

\section{Corresponding author}

L. Lambert, Department of Radiology, General University Hospital in Prague, U Nemocnice 2, 12808 Prague 2, Czech Republic. Fax: +420 224963048. E-mail: lambert.lukas@gmail.com

\section{Introduction}

Intimal hyperplasia (IH) is an excessive response to the intimal injury or altered hemodynamics. It occurs in the distal femoro-popliteal anastomosis between 2 and 24 months postoperatively due to abnormal blood flow with altered wall shear stress (WSS) (Bassiouny et al. 1992, Tiwari et al. 2003). On a microscopic level, IH is characterized by migration of smooth muscle cells from the media, their proliferation and matrix synthesis in the intima, a process which ultimately results in stenosis (O’Brien et al. 2007).

WSS is a friction force between the vessel wall and the blood flow. Therefore it is parallel to the flow direction and its relation with the blood velocity, viscosity and diameter of the vessel can be expressed as:

$$
W S S=\frac{\text { blood velocity } \times \text { blood viscosity }}{\text { vessel diameter }}
$$

(Bassiouny et al. 1992, Haruguchi and Teraoka 2003, Keynton et al. 2001).

The influence of WSS on the endothelium plays a pivotal role in the early development of $\mathrm{IH}$ and early stenosis of the reconstruction. Previously, attempts have been made to optimize flow and WSS particularly by modifying the geometry of the anastomosis or the compliance of the bypass (Neville et al. 2011, Tiwari et al. 2003). In this study we hypothesized that a more acute anastomosis angle would result in more favorable flow and distribution of the WSS in the distal end-to-side anastomosis (Leon and Greisler 2003). 


\section{Material and Methods}

In this experimental in vitro study, we researched and constructed a model of a distal infrainguinal anastomosis (Fig. 1) based on preliminary experiments and driven by theories of interaction between the blood flow and vessel wall reported in the literature (Grus et al. 2007, 2009, Haruguchi and Teraoka 2003, Keynton et al. 2001).

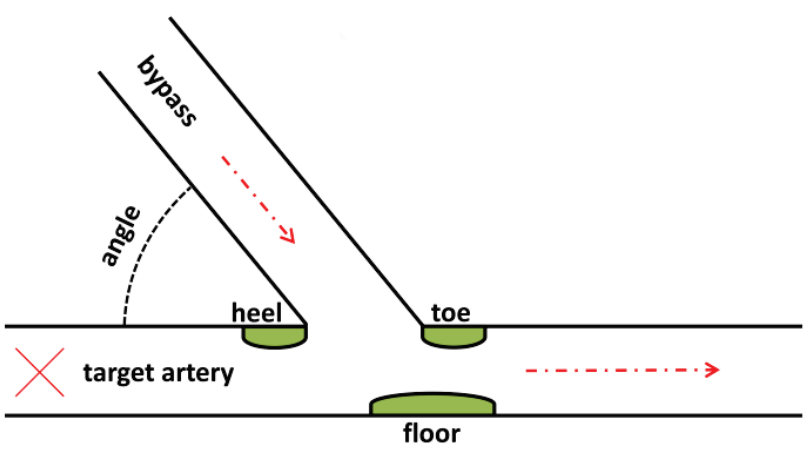

Fig. 1. Schematic drawing of the anastomosis with common locations of intimal hyperplasia at the toe, heel and floor of the anastomosis. To simplify the model, we decided to simulate the most common condition, where the target artery is occluded (X) and the only inflow comes from the bypass.

\section{The anastomosis model had the following parameters}

The diameter of the target vessel and the bypass was $6 \mathrm{~mm}$, which is the most common diameter of grafts used in infrainguinal reconstructions. The anastomosis angles were $60^{\circ}, 45^{\circ}$ and $25^{\circ}$. These values are encountered in infrainguinal bypass reconstructions and they also had been used previously (Fei et al. 1994, Grus et al. 2009, Hoedt et al. 2015). The length of the evaluated segment was chosen according to the common location of IH that develops predominantly in the anterior (upper) wall of the target vessel 15 to $20 \mathrm{~mm}$ distally from the toe of the anastomosis and less frequently, on the posterior (bottom) wall about 12-13 $\mathrm{mm}$ from the heel of the anastomosis (Fig. 1). The flow rates of $80 \mathrm{ml} / \mathrm{min}$, $200 \mathrm{ml} / \mathrm{min}$, and $500 \mathrm{ml} / \mathrm{min}$ that correspond with resting, walking and running were modeled by corresponding Reynolds numbers $(500,1000$, and 1400) with respect to the similarity theory that implies that the flow in the model and in vivo are similar if the values of the Reynolds number are similar (Hoedt et al. 2015, Loth et al. 2008). The inflow into the bypass was modulated to simulate natural pulsatile flow as recorded by a Pulsed Wave (PW) Doppler ultrasound during routine examination in healthy human subjects. As a working fluid, water with polyamide particles $20 \mu \mathrm{m}$ in diameter was chosen (Grus et al. 2007). The casing of the model was created from plexiglass by lost wax casting. To simplify the model, we decided to simulate the most common condition, where the target artery is occluded and the only inflow comes from the graft. To visualize the flow and WSS two methods were used. In particle image velocimetry (PIV) the working fluid with polyamide particles is illuminated by a red laser diode $(\lambda=660 \mathrm{~nm})$. The beam is focused by a lens to create a plane. The light reflected from the particles is recorded by a high speed camera and their motion, which represents the flow, is subsequently visualized (Grus et al. 2007). The distribution of WSS was calculated from PIV using advanced computational fluid dynamics (CFD) software (ANSYS Fluent, ANSYS Inc., Canonsburg, PA).

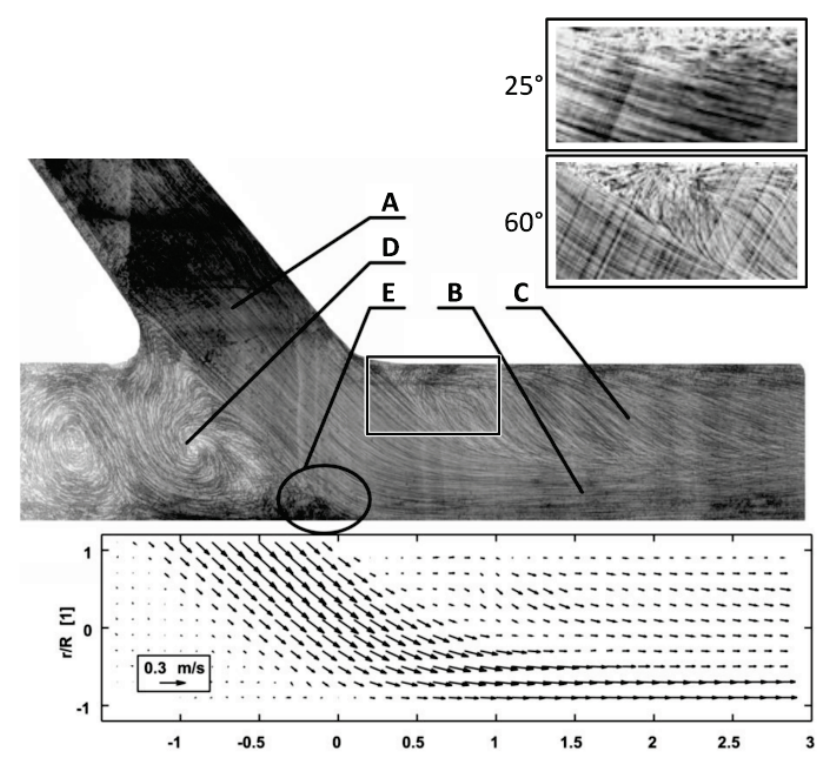

Fig. 2. Visualization of flow in the anastomosis with the bypass connected at $45^{\circ}$ degrees angle using particle image velocimetry (middle). A: inflow to the anastomosis from the bypass; B: outflow from the anastomosis - laminar flow; C: outflow from the anastomosis - turbulent flow; D: vortex at the heel of the anastomosis; E: area with a high velocity gradient. The image below shows the flow velocity vector field. Comparison of magnified visualization of the flow in the toe of the anastomosis for $25^{\circ}$ and $60^{\circ}$ anastomosis shown in the right upper corner demonstrates that with the $25^{\circ}$ design the stagnation point disappears altogether and the flow becomes laminar.

\section{Results}

Visualization of the flow and flow velocity field in the $45^{\circ}$ anastomosis is shown in Figure 2. Comparison of images from the flow visualization by PIV revealed that turbulent flow at the toe of the anastomosis was markedly reduced in the $25^{\circ}$ anastomosis compared to 
$45^{\circ}$ and $60^{\circ}$ (Fig. 3). At the stagnation point at the toe of the anastomosis, (which is a common location of $\mathrm{IH}$ ) the vertical flow in the $25^{\circ}$ model disappeared completely (Fig. 3).

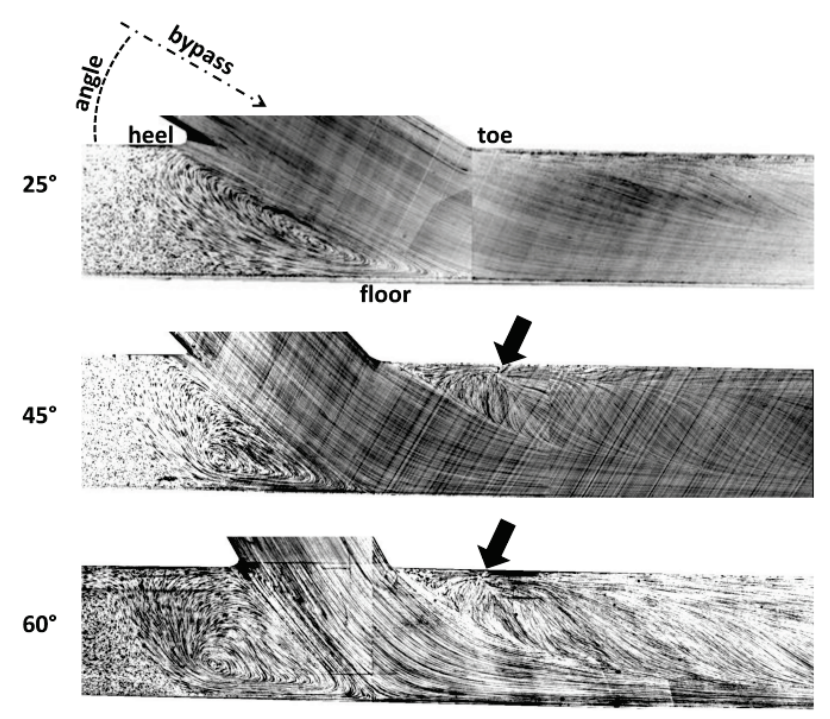

Fig. 3. Comparison of flow $(\mathrm{Re}=1000)$ in the anastomosis with $25^{\circ}, 45^{\circ}$, and $60^{\circ}$ angle shows that the vortex (arrow) at the toe of the anastomosis that is present in the $60^{\circ}$ and $45^{\circ}$ design disappears in the $25^{\circ}$ anastomosis, which has a more favorable flow pattern at the heel and the floor of the anastomosis as well.

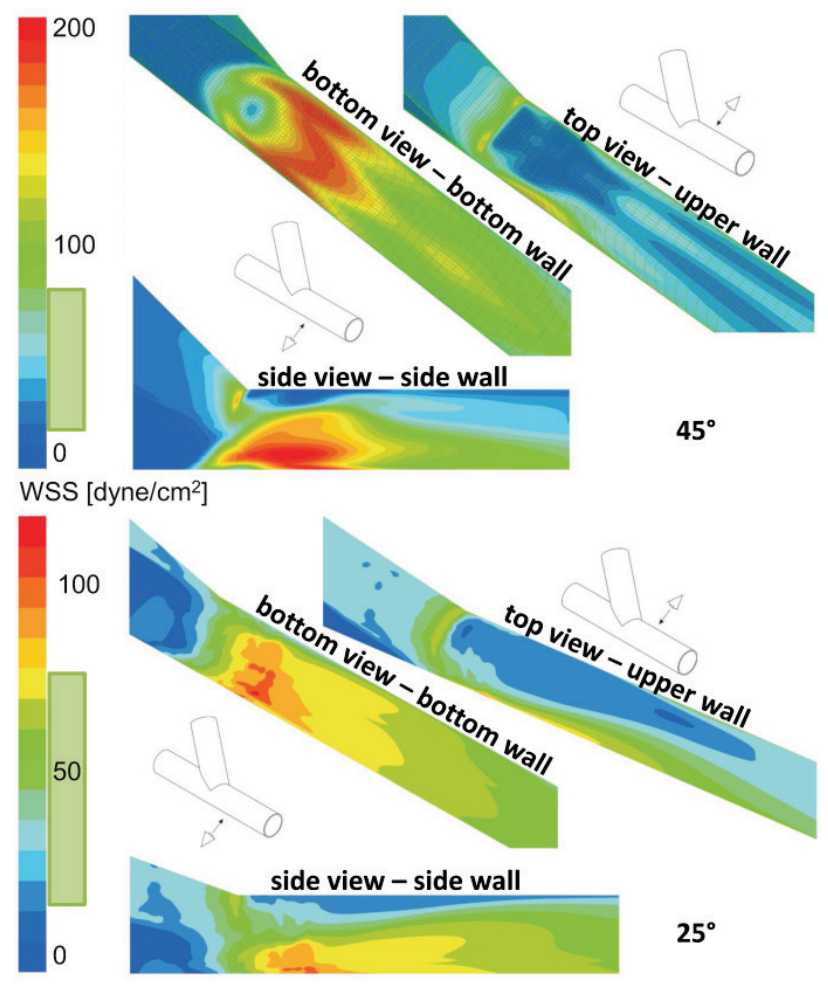

Fig. 4. Distribution of WSS in the $45^{\circ}$ (above) and $25^{\circ}$ (below) anastomosis shows locations with too low values (dark blue) that stimulate intimal hyperplasia and with too high values (red) that cause direct mechanical injury to the endothelial cells including its epitopes. Green vertical bars delineate physiological WSS values. Note that the two scales have a different range.
Visualization of the data from PIV using CFD (Fig. 4) demonstrated that the transition from a turbulent flow to a laminar flow occurred more distally in the $45^{\circ}$ compared to the $25^{\circ}$ anastomosis. In the $25^{\circ}$ anastomosis the flow passed the critical section in a laminar fashion and some whirling occurred more distally. Unlike in the $45^{\circ}$ anastomosis, the distribution of WSS in the $25^{\circ}$ anastomosis showed nearly physiological (10-70 dyne $/ \mathrm{cm}^{2}$ ) values (Fig. 4) (Ene-Iordache and Remuzzi 2012).

\section{Discussion}

In this work we attempted to optimize the geometry of the distal infrainguinal anastomosis by modifying its angle and we evaluated the flow visualized by PIV and WSS maps obtained by CFD. The visualization of the flow in the anastomosis clearly indicated that construction of an anastomosis with an acute angle resulted in a more favorable flow in the anastomosis that is known to reduce formation of intimal hyperplasia - remodeling of the vessel wall otherwise responsible for early failure of the reconstruction. In clinical practice, the most common locations of such changes occur in the areas with disturbed blood flow: predominantly in the toe, less frequently in the heel, and the floor of the anastomosis (Grus et al. 2009).

The results of this experimental study are in accordance with previous studies that showed the relationship between $\mathrm{IH}$ and geometry of the anastomosis. A more acute anastomosis angle results in better hemodynamics in the anastomosis and a lower risk of IH and early graft failure (Grus et al. 2009). Decreasing the anastomosis angle results in the disappearance of the stagnation point at the toe of the anastomosis (Fig. 3), and also preservation of the laminar flow and of the physiological WSS values (10-70 dyne $/ \mathrm{cm}^{2}$, Fig. 4) (Ene-Iordache and Remuzzi 2012, Kamiya and Togawa 1980). Increased WSS causes direct mechanical injury to the endothelial cells including the glycocalyx while too low WSS results in stimulation of the endothelial cells, proliferation of the smooth muscle cells, their migration into the intima and synthesis of extracellular matrix (Jackson et al. 2009). The link between low WSS and IH has already been established in venous grafts (Allaire and Clowes 1997) and some studies even suggest a protective effect of normal WSS (Malek et al. 1999, Passerini et al. 2003, Wu et al. 2004).

The influence of the blood flow on the formation of IH is very complex and also changes in the stimulation 
pattern of the mechanoreceptors located on the wall and mechanical coupling of the glycocalyx with the cytoskeleton induce the production of various growth factors, cytokines, modulate the synthesis and release of vasoactive substances (NO, prostacyclin I2) and intercellular adhesion molecules (Davies 2009, Johnson et al. 2011, Zeng and Tarbell 2014). Macrophages that infiltrate the media can be demonstrated as early as $6 \mathrm{~h}$ from the construction of the bypass (Davies 2009). Smooth muscle cells from the vessel wall that proliferate also alter their metabolic activity and begin to synthesize extracellular matrix that contributes to the narrowing of the vessel.

The use of a supplementary cuff between the graft and the target artery is controversial, but as CFD simulations showed, it can also be optimized in terms of the length-to-height ratio of the boot (Xiong and Chong 2009). In vivo, a supplementary cuff produces less favorable flow than a vein patch which approximates the straight anastomotic pattern (Neville et al. 2011). The ratio between the diameter of the target vessel and the bypass has an influence on the hemodynamics as well. The best parameters are achieved when the graft has the same or a greater diameter than the target artery (Qiao and Liu 2006). Furthermore, all these flow optimizations may be improved by connecting the graft and the target artery in a more acute angle of incidence. However, construction of an anastomosis at a more acute angle also has its implications: it requires longer arteriotomy and suture and such structure is therefore more technically difficult to embed. Finally, it is the skill and experience of the surgeon what dictates the surgical technique and the ultimate outcome of the patient (Tan et al. 2012).

In conclusion, decreasing the distal anastomosis angle in a femoropopliteal bypass results in more favorable hemodynamics including the flow pattern and WSS in locations susceptible to IH.

This in vitro study has several limitations. Firstly, although the inflow of the target artery becomes occluded in the majority of patients due to competitive flow from the bypass, minimal residual flow may reduce the negative influence of the hemodynamics at the floor of the anastomosis in a minority of them (Kute and Vorp 2001). Secondly, we used a rigid model and therefore issues related to compliance mismatch could not be studied (Tiwari et al. 2003). Thirdly, an in vivo anastomosis is always more complex in shape and this is even more pronounced in special adjustments such as cuffs of patches (Ducasse et al. 2004). Lastly, unlike in our in vitro model, the in vivo target artery physiologically responds to flow changes induced by the conduit (Davies 2009).

\section{Conflict of Interest}

There is no conflict of interest.

\section{Acknowledgements}

This article was supported by the following grants: PRVOUK P27/LF1/1, NT13302-4/2012, 15-27941A.

\section{References}

ALLAIRE E, CLOWES AW: Endothelial cell injury in cardiovascular surgery: the intimal hyperplastic response. Ann Thorac Surg 63: 582-591, 1997.

BASSIOUNY HS, WHITE S, GLAGOV S, CHOI E, GIDDENS DP, ZARINS CK: Anastomotic intimal hyperplasia: mechanical injury or flow induced. J Vasc Surg 15: 708-716, 1992.

DAVIES PF: Hemodynamic shear stress and the endothelium in cardiovascular pathophysiology. Nat Rev Cardiol 6: 16-26, 2009.

DUCASSE E, FLEURISSE L, VERNIER G, SPEZIALE F, FIORANI P, PUPPINCK P, CREUSY C: Interposition vein cuff and intimal hyperplasia: an experimental study. Eur J Vasc Endovasc Surg 27: 617-621, 2004.

ENE-IORDACHE B, REMUZZI A: Disturbed flow in radial-cephalic arteriovenous fistulae for hemodialysis: low and oscillating shear stress locates the sites of stenosis. Nephrol Dial Transplant 27: 358-368, 2012.

FEI D-Y, THOMAS JD, RITTGERS SE: The effect of angle and flow rate upon hemodynamics in distal vascular graft anastomoses: a numerical model study. J Biomech Eng 116: 331-336, 1994.

GRUS T, LINDNER J, VIK K, TOSOVSKÝ J, MATECHA J, NETREBSKÁ H, TŮMA J, ADAMEC J: Particle image velocimetry measurement in the model of vascular anastomosis. Prague Med Rep 108: 75-86, 2007. 
GRUS T, LINDNER J, VIDIM T, TOSOVSKY J, MATECHA J, ROHN V, LAMBERT L, GRUSOVA G: The anastomosis angle is a key to improved long-term patency of proximal femoropopliteal bypass. Ann Vasc Surg 23: 598-605, 2009.

HARUGUCHI H, TERAOKA S: Intimal hyperplasia and hemodynamic factors in arterial bypass and arteriovenous grafts: a review. J Artif Organs 6: 227-235, 2003.

HOEDT M, HOW T, POYCK P, WITTENS C: Why patencies of femoropopliteal bypass grafts with distal end-to-end anastomosis are comparable with end-to-side anastomosis. Ann Thorac Cardiovasc Surg 21: 157-164, 2015.

JACKSON M, WOOD NB, ZHAO S, AUGST A, WOLFE JH, GEDROYC WMW, HUGHES AD, THOM SAM, XU $\mathrm{XY}$ : Low wall shear stress predicts subsequent development of wall hypertrophy in lower limb bypass grafts. Artery Res 3: 32-38, 2009.

JOHNSON BD, MATHER KJ, WALLACE JP: Mechanotransduction of shear in the endothelium: basic studies and clinical implications. Vasc Med 16: 365-377, 2011.

KAMIYA A, TOGAWA T: Adaptive regulation of wall shear stress to flow change in the canine carotid artery. Am J Physiol 239: H14-H21, 1980.

KEYNTON RS, EVANCHO MM, SIMS RL, RODWAY NV, GOBIN A, RITTGERS SE: Intimal hyperplasia and wall shear in arterial bypass graft distal anastomoses: an in vivo model study. J Biomech Eng 123: 464-473, 2001.

KUTE SM, VORP DA: The effect of proximal artery flow on the hemodynamics at the distal anastomosis of a vascular bypass graft: computational study. J Biomech Eng 123: 277-283, 2001.

LEON L, GREISLER HP: Vascular grafts. Expert Rev Cardiovasc Ther 1: 581-594, 2003.

LOTH F, FISCHER PF, BASSIOUNY HS: Blood flow in end-to-side anastomoses. Annu Rev Fluid Mech 40: 367-393, 2008.

MALEK AM, ALPER SL, IZUMO S: Hemodynamic shear stress and its role in atherosclerosis. JAMA 282: 2035-2042, 1999.

NEVILLE RF, ELKINS CJ, ALLEY MT, WICKER RB: Hemodynamic comparison of differing anastomotic geometries using magnetic resonance velocimetry. J Surg Res 169: 311-318, 2011.

O'BRIEN TP, WALSH MT, KAVANAGH EG, FINN SP, GRACE PA, MCGLOUGHLIN TM: Surgical feasibility study of a novel polytetrafluoroethylene graft design for the treatment of peripheral arterial disease. Ann Vasc Surg 21: 611-617, 2007.

PASSERINI AG, MILSTED A, RITTGERS SE: Shear stress magnitude and directionality modulate growth factor gene expression in preconditioned vascular endothelial cells. J Vasc Surg 37: 182-190, 2003.

QIAO A, LIU Y. Influence of graft-host diameter ratio on the hemodynamics of CABG. Biomed Mater Eng 16: 189201, 2006.

TAN T-W, KALISH JA, HAMBURG NM, RYBIN D, DOROS G, EBERHARDT RT, FARBER A: Shorter duration of femoral-popliteal bypass is associated with decreased surgical site infection and shorter hospital length of stay. J Am Coll Surg 215: 512-518, 2012.

TIWARI A, CHENG K-S, SALACINSKI H, HAMILTON G, SEIFALIAN AM: Improving the patency of vascular bypass grafts: the role of suture materials and surgical techniques on reducing anastomotic compliance mismatch. Eur J Vasc Endovasc Surg 25: 287-295, 2003.

WU SP, RINGGAARD S, OYRE S, HANSEN MS, RASMUS S, PEDERSEN EM: Wall shear rates differ between the normal carotid, femoral, and brachial arteries: an in vivo MRI study. J Magn Reson Imaging 19: 188-193, 2004.

XIONG FL, CHONG CK: Numerical study of the influence of anastomotic configuration on hemodynamics in Miller cuff models. Ann Biomed Eng 37: 301-314, 2009.

ZENG Y, TARBELL JM: The adaptive remodeling of endothelial glycocalyx in response to fluid shear stress. PloS One 9: e86249, 2014. 